\title{
Peripheral plasmablasts in anti-MuSK myasthenia gravis
}

\author{
Guillermo Delgado-García, Teresa Corona-Vázquez \\ Clinical Laboratory of Neurodegenerative Diseases, National Institute of Neurology and Neurosurgery, Mexico City 14269, Mexico. \\ Correspondence to: Prof. Teresa Corona-Vázquez, Clinical Laboratory of Neurodegenerative Diseases, National Institute of Neurology and \\ Neurosurgery, Insurgentes Sur \#3877, Col. La Fama, Del. Tlalpan, Mexico City 14269, Mexico. E-mail: coronav@unam.mx \\ How to cite this article: Delgado-García G, Corona-Vázquez T. Peripheral plasmablasts in anti-MuSK myasthenia gravis. Neuroimmunol \\ Neuroinflammation 2017;4:236-7.
}

Article history: Received: 4 Aug 2017 Accepted: 25 Aug 2017 Published: 9 Nov 2017

As Hong and Sung ${ }^{[1]}$ previously did, we read with great interest the study published by Guptill et al. ${ }^{[2]}$ They reported that anti-muscle-specific kinase (MuSK) myasthenia gravis patients and healthy controls had similar percentages of peripheral plasmablasts. This result is derived from a comparison between 13 female patients (out of the 18 originally included in the study) and 6 controls ${ }^{[2]}$. Taking into account the effect of rituximab on peripheral plasmablasts ${ }^{[3]}$, those patients treated with it $(n=3)$ were not included in the previous comparison. Excluding these patients, $6(40 \%)$ were on chronic prednisone treatment, whose dose was between $2.5 \mathrm{mg}$ every other day and $20 \mathrm{mg}$ daily. However, it is already known that prednisone therapy effectively decreases peripheral plasmablasts ${ }^{[4]}$, so this could contribute to the lack of difference between patients and controls. They also reported that immunosuppressed $(n=7)$ and non-immunosuppressed $(n=6)$ patients had similar percentages of peripheral plasmablasts. A comparison between non-immunosuppressed patients and controls would have also been quite informative, since it would eliminate the prednisone factor and facilitate the demonstration of a difference between a seemingly normal population of peripheral plasmablasts (controls) and an abnormal one (patients). Finally, vaccination history in controls is also an important point to consider, since it has been documented that peripheral plasmablasts increase after vaccination ${ }^{[5]}$.

Increased peripheral plasmablasts have been found in various immune-based diseases. IgG4-related disease is one of these conditions ${ }^{[6]}$. In connection with the above, Raibagkar et al. ${ }^{[7]}$ recently reported the case of a 54-year-old woman with anti-MuSK myasthenia gravis who also developed retroperitoneal lymphadenopathy histopathologically consistent with IgG4-related disease. They did not report the count of peripheral plasmablasts in this patient. We conducted a search in PubMed and found an additional case of a 72-year-old man with myasthenia gravis who also developed an inflammatory aortic aneurysm. The latter was compatible with a possible diagnosis of IgG4related disease. Nevertheless, the antibody involved in the diagnosis of myasthenia gravis in this patient is not reported $^{[8]}$.

In the title of their short communication, Raibagkar et al. ${ }^{[7]}$ wonder if there is any relationship between the two diseases. It is interesting to note that in anti-MuSK License (https://creativecommons.org/licenses/by/4.0/), which permits unrestricted use, distribution, and reproduction in any medium, as long as the original author is credited and the new creations are licensed under the identical terms.

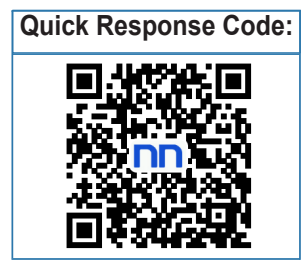


myasthenia gravis antibodies are directly pathogenic ${ }^{[9]}$, whereas in IgG4-related disease they are probably not $^{[7,10]}$. We recently stressed that the sphere of IgG4mediated neurological autoimmune disorders is an expanding one ${ }^{[10]}$. We believe that the study of the ties between IgG4-mediated neurological autoimmune disorders and IgG4-related disease could represent a very fruitful field in the near future ${ }^{[10]}$, so further studies are needed in this specific area. However, one of the limitations that these studies might face is the low prevalence (or underdiagnosis) of these conditions ${ }^{[11,12]}$. Multicentric studies through international, collaborative efforts could mitigate this limitation. Regarding the technical aspects, it is also necessary to unify the characterization (gating) of peripheral plasmablasts in order to facilitate dialogue and exchange between different research communities, which may come from different domains of specialization (neurology, rheumatology, immunology, among others).

\section{DECLARATIONS}

\section{Authors' contributions}

Literature review, significant contribution to intellectual manuscript content, and manuscript drafting: G. Delgado-García, T. Corona-Vázquez.

\section{Financial support and sponsorship None.}

\section{Conflicts of interest}

There are no conflicts of interest.

\section{Patient consent Not applicable.}

\section{Ethics approval \\ Not applicable.}

\section{REFERENCES}

1. Hong YH, Sung JJ. Auto-reactive B cells in MuSK myasthenia gravis. Neuroimmunol Neuroinflammation 2016;3:196-7.

2. Guptill JT, Yi JS, Sanders DB, Guidon AC, Juel VC, Massey JM, Howard JF Jr, Scuderi F, Bartoccioni E, Evoli A, Weinhold KJ. Characterization of B cells in muscle-specific kinase antibody myasthenia gravis. Neurol Neuroimmunol Neuroinflamm 2015;2:e77.

3. Wallace ZS, Mattoo H, Carruthers M, Mahajan VS, Della Torre E, Lee H, Kulikova M, Deshpande V, Pillai S, Stone JH. Plasmablasts as a biomarker for IgG4-related disease, independent of serum IgG4 concentrations. Ann Rheum Dis 2015;74:190-5.

4. Iwata S, Saito K, Hirata S, Tanaka Y. Phenotypic changes of lymphocyte in a patient with IgG4-related disease after corticosteroid therapy. Ann Rheum Dis 2012;71:2058-9.

5. Maecker HT, McCoy JP, Nussenblatt R. Standardizing immunophenotyping for the Human Immunology Project. Nat Rev Immunol 2012;12:191-200.

6. Koarada S, Tada Y. Roles of plasmablasts in IgG4-related disease and various immune-based diseases. World J Rheumatol 2016;6:16-22.

7. Raibagkar P, Ferry JA, Stone JH. Is MuSK myasthenia gravis linked to IgG4-related disease? J Neuroimmunol 2017;305:82-3.

8. Jun H, Jung CW. Immunoglobulin G4-related inflammatory abdominal aortic aneurysm associated with myasthenia gravis, with contained rupture. Vasc Endovascular Surg 2016;50:571-4.

9. Huijbers MG, Zhang W, Klooster R, Niks EH, Friese MB, Straasheijm KR, Thijssen PE, Vrolijk H, Plomp JJ, Vogels P, Losen M, Van der Maarel SM, Burden SJ, Verschuuren JJ. MuSK IgG4 autoantibodies cause myasthenia gravis by inhibiting binding between MuSK and Lrp4. Proc Natl Acad Sci U S A 2013;110:20783-8.

10. Delgado-García G, Corona-Vázquez T. IgG4-related disease and IgG4mediated neurological autoimmune disorders: one and the same? $J$ Neuroimmunol 2017;310:129-30.

11. Huijbers MG, Querol LA, Niks EH, Plomp JJ, van der Maarel SM, Graus F, Dalmau J, Illa I, Verschuuren JJ. The expanding field of IgG4-mediated neurological autoimmune disorders. Eur J Neurol 2015;22:1151-61.

12. Brito-Zerón P, Ramos-Casals M, Bosch X, Stone JH. The clinical spectrum of IgG4-related disease. Autoimmun Rev 2014;13:1203-10. 